\title{
Study on the Musical Language and Structure of the String Quartets of Shostakovich in Later Period
}

\author{
Lin Dongfang \\ Northwest Normal university of music, Lanzhou, Gansu,730070 China \\ 252078668@qq.com
}

Keywords: Shostakovich; string quartets in later period; musical language; structure study

\begin{abstract}
This paper focuses on analyzing and elaborating the quartet works of Shostakovich in later period, defines the status and influences of later-period quartet in the entire creative history of the composer, and gives accurate and proper explanation on connotations, artistic conception and composer's creative conception contained.
\end{abstract}

\section{Introduction}

As a "pure soviet" composer, Shostakovich has had the extremely important status in Soviet music or even world music in the $20^{\text {th }}$ century: On the one hand, he was one of minorities of composers insisting in applying traditional musical vocabularies and composition methods under the historical background when various new-type musical languages and presentations emerged in endlessly in the $20^{\text {th }}$ century. On the other hand, his music style totally differed from senior composers, showing the personal characteristics and contemporary temperament. The contradictory creative characteristic was determined by his personality and life experience: Shostakovich formed the musical language style with double characteristic in the long-term creative practice. The style mingled with the tradition and modernity also shows that the double connotations in works and double conflicts in personality. As a result, in order to know about Shostakovich creation, it is necessary to comprehend and study the special musical language style. The creative style is fully displayed in string quartets, which is called as the "inner diary" of the composer, thus it is inevitable to study the quartet.

\section{The first stage of string quartets}

String quartets have the time-honored history as the traditional chamber music style form. Starting from Joseph Haydn to confirm standards of string quartets, this genre has become the touchstone in pure music writing of the composer. Starting from Beethoven, Brahms to Schoenberg and Bartok in the $20^{\text {th }}$ century, all of them have had the excellent quartet works. The string quartets of Beethoven are the unbridgeable peak in the classical quartet field. Six string quartets created by the Hungarian composer Bela Bartok have become influential works in genre creation of the $20^{\text {th }}$ century. Fifteen string quartets by Shostakovich were also one of important literatures in $20^{\text {th }}$ century in this field. As a successful symphonist, quartets of Shostakovich have been mutually correlated with symphony composition in many aspects. The creative means applied by the composer in symphony were also created in quartet composition, so as to be featured with the abundant "symphonic theatricality.

The $9^{\text {th }}$ string quartet was created four years later after creating the $8^{\text {th }}$ quartet. It has had an obvious difference from the $7^{\text {th }}$ and $8^{\text {th }}$ quartets in musical language. The creation of four quartets from the $6^{\text {th }}$ quartet to $8^{\text {th }}$ quartet was considered as an integral whole. By learning from psychological analysis of Lacan, “modern subject” of Zizek, “epic” and "novel” of Bakhtin, the modern principal consciousness presented in four quartets is explained: in the paper, the author analyzed the quartets from the $6^{\text {th }}$ quartet to the $8^{\text {th }}$ quartet to describe the gradually cracked process of "realistic subject" in Zizek theory, showing that quartets from the $6^{\text {th }}$ quartet to the $8^{\text {th }}$ quartet have had the gradually strengthening process of morbid psychology features. Meanwhile, by using the theoretical analysis of biblical hermeneutics, it can be observed that the destruction is gradually consistent with the 
cataclysmic genesis process in "revelation". Under the circumstance, it has the innocent fantasy, while individual destruction tendency has already hidden in it.

First movement: fluent middle plate analysis. The $9^{\text {th }}$ string quartet selected the structural form of continuous performance in five movements, just like the $8^{\text {th }}$ quartet. After the $8^{\text {th }}$ quartet attempted to write the first movement in the fugue form, Shostakovich returned to the structural framework of sonata form in the standard "thematic development" of musical language framework. Similarly, it didn't apply the standard sonata form, but used the changes without development to reappear the simple sonata form.

Table 1 The overall structure of the first movement in the $9^{\text {th }}$ string quartet

\begin{tabular}{|c|c|c|c|c|c|c|c|}
\hline \multicolumn{8}{|c|}{ The $9^{\text {th }}$ string quartet p.117 I: Moderato con moto } \\
\hline \multicolumn{4}{|c|}{ Exposition } & \multicolumn{4}{|c|}{ Recapitulation } \\
\hline \multicolumn{2}{|c|}{ Principal theme } & $\begin{array}{l}\text { Secondary } \\
\text { theme }\end{array}$ & $\begin{array}{l}\text { Ending } \\
\text { part }\end{array}$ & $\begin{array}{l}\text { Principal } \\
\text { theme }\end{array}$ & $\begin{array}{l}\text { Secondary } \\
\text { theme }\end{array}$ & Connection & End \\
\hline \multicolumn{2}{|c|}{$1-26-44$} & $45-77$ & $78-90$ & $91-110$ & $111-124$ & $125-150$ & $151-169$ \\
\hline$E^{b}$ & $E^{\mathrm{b}} \cdot \mathrm{D} \cdot \mathrm{b}^{\mathrm{b}}$ & $b^{b}-f$ & $b^{b}-E^{b}$ & $\mathrm{E}^{\mathrm{b}}$ & C & $c-A-E^{b}$ & $E^{b}$ \\
\hline
\end{tabular}

The $9^{\text {th }}$ string quartet created by using the thematic technique elaborates the thematic core motivation in the first statement process of the principal theme in the exposition. The starting of the exposition displays the presentation of overlapping layer by layer: first of all, two lower parts have the continuous prolonged sound $b_{e}$. Based on it, the second fiddle performs the "chattering" motivation with the subject of second-degree fluctuation constituted by $b_{e}-f$ sound. The stable $b_{e}$ tone sphere and sound background are formed by virtue of continuous long-term keynote. Based on the sound background, the first violin performs the chanting principal theme of exposition:

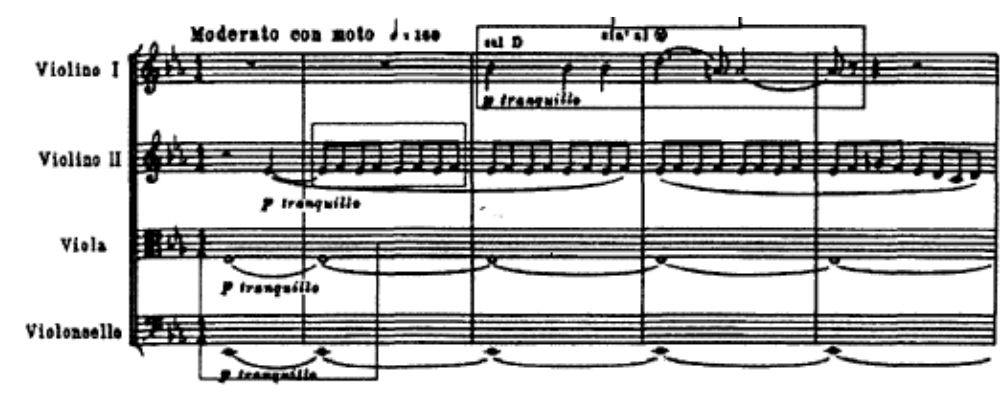

Fig. 1 The Principal Theme of the First Movement in the $9^{\text {th }}$ String Quartet

The principal theme of exposition has the full length of 16 bars, which are composed of the second-sound core motivation $\mathrm{B}^{\mathrm{b}}$-D-A of three-bar length. The core motivation includes three different interval structures: tautophony, upward second degree and fourth degree tone. The core motivation is marked as motivation A. The motivation A is extremely similar to the "zigzag" tone morphology of the $8^{\text {th }}$ ensemble signature motivation in the external structural morphology.

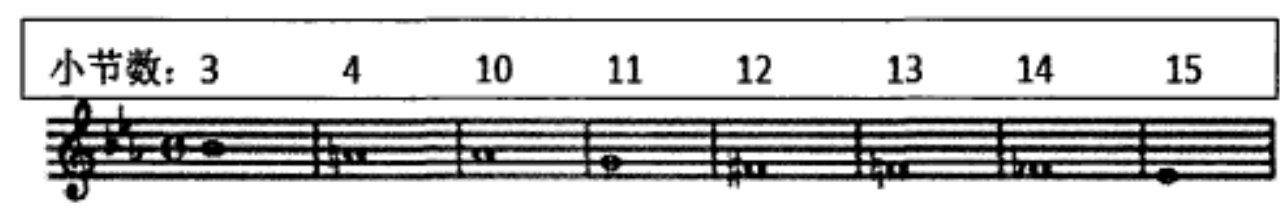

Fig.2 The Thematic Rhythm Structure Diagram of the First Movement in the $9^{\text {th }}$ String Quartet

In the development of principal theme, the theme doesn't use the strict motivation split repetition as the developmental features, but presents in the freely developed feature, because Shostakovich has had the typical creative thinking of Russian composer. The creative thinking is the "linear" musical conception with oriental features differing from the "massive" thinking of German and Austria 
composers. The principal part is the continuous mist, showing some lazy personality and giving priority to static state.

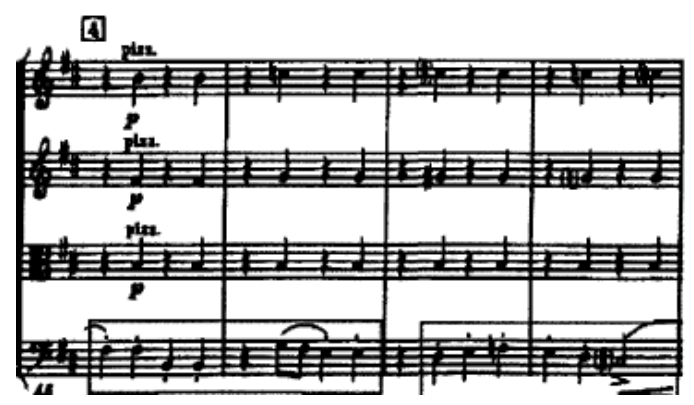

Fig.3 The Secondary Theme of the First Movement in the $9^{\text {th }}$ String Quartet

The secondary theme belongs to the four-bar structure. It is composed of two obvious motivations: the previous motivation uses the bright rhythm as the obvious feature. It is composed of downward five-degree skipping and bacchius rhythm. The downward leap of the motivation contrasts with the uptrend of the principal part. Here is called as the motivation B.

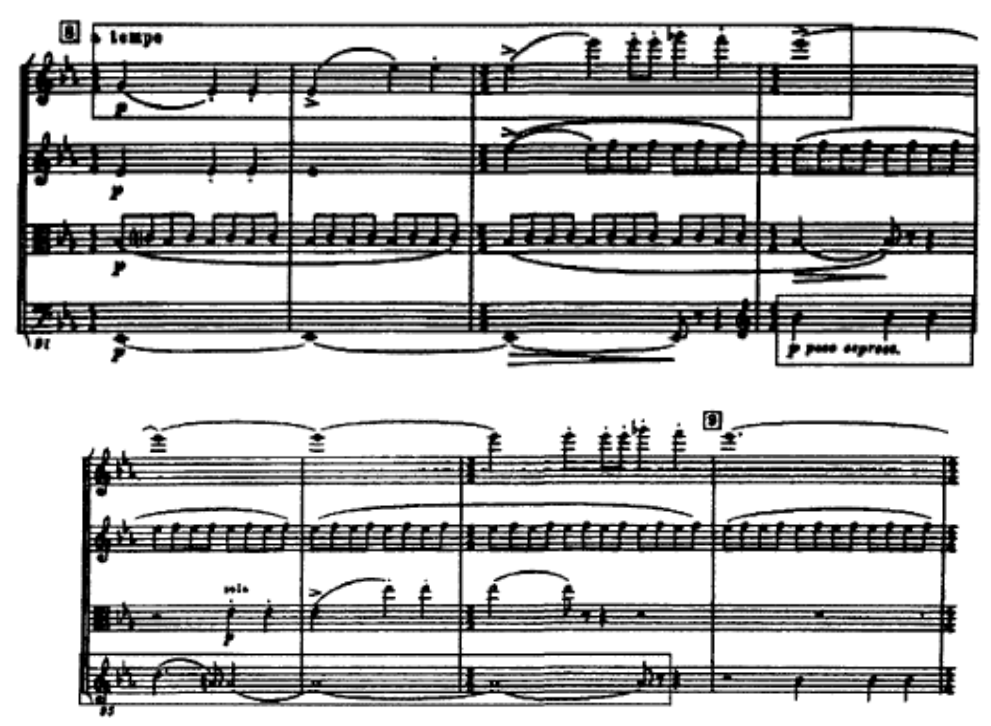

Fig.4 The Principal Reappearance of the First Movement in the $9^{\text {th }}$ String Quartet

The another motivation includes the arc-shaped four-tone motivation of $C^{\#}, \mathrm{D}, \mathrm{E}$ and F. Here, the motivation is called as the motivation $\mathrm{C}$. The four-tone motivation is ranked as the semitone, whole tone and semitone structure. The assemble prototype is 4-3[0,1,3,4], because the composer frequently used DSCH signature motivation in the previous $7^{\text {th }}$ and $8^{\text {th }}$ quartets, showing that the $9^{\text {th }}$ string quartet had a close relation with the $7^{\text {th }}$ and $8^{\text {th }}$ quartets: in the $9^{\text {th }}$ string quartet, the principal theme continues the external form of signature motivation, while the secondary theme continues the interval structure of signature motivation, thus the creative conception of the $9^{\text {th }}$ quartet obviously connects with the $8^{\text {th }}$ quartet. The motivation $C$ is frequently changed in this quartet. In the $8^{\text {th }}$ quartet, the composer used the signature motivation to reach the best balance between the public and the private. The $9^{\text {th }}$ string quartet inherits the feature, translates the integrated signature motivation into two different thematic forms and further develops the fifth movement into the scattered obscure thematic exhibition, thus it shows that the composer was attempting to premise and development in the $9^{\text {th }}$ string quartet by virtue of the signature motivation, hoping to state the unfinished truth in the $8^{\text {th }}$ quartet.

The third movement: Allegretto: by analyzing the previous two movements, we assume that this quartet uses the secondary theme of the first movement as the core material to develop. In other words, it continues the "signature motivation" of the $8^{\text {th }}$ quartet to develop. After the first statement of the first movement, the second movement finishes the elegy development of "signature motivation". In the scherzo of the third movement, the signature motivation is comprehensively displayed. The 
movement is the typical scherzo movement of Shostakovich: the versatile musical character, straightforward texture presentation, and order structural form. The structure of the entire movement is the trilogy with the mixed symmetric principle and local variation principle.

Table 2 The Overall Structure of the Third Movement in the $9^{\text {th }}$ String Quartet

\begin{tabular}{|c|c|c|c|c|c|c|c|c|}
\hline \multicolumn{9}{|c|}{ The $9^{\text {th }}$ string quartet op.117 III, Allegretto } \\
\hline \multicolumn{4}{|c|}{$\mathrm{A}$} & $\mathrm{B}$ & \multicolumn{4}{|c|}{ 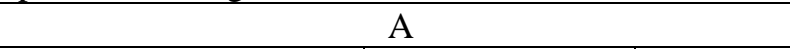 } \\
\hline \multicolumn{2}{|c|}{$\mathrm{a}$} & $\mathrm{b}$ & & $\mathrm{C}$ & \multicolumn{2}{|c|}{$\mathrm{b}$} & $\mathrm{a}$ & End \\
\hline $1-49$ & $0-60$ & $61-128$ & $129-136$ & $137-190$ & $191-209$ & $210-217$ & 218-231-265 & $266-281$ \\
\hline & $f$ & \multicolumn{2}{|c|}{$\mathrm{c}-\mathrm{a}$} & $\mathrm{a}$ & \multicolumn{2}{|c|}{$\mathrm{a}-\mathrm{c}$} & \multicolumn{2}{|c|}{$\#_{\mathrm{f}}$} \\
\hline
\end{tabular}

Table 3 The Second Movement A-a Structure of the $9^{\text {th }}$ String Quartet

\begin{tabular}{|c|c|c|}
\hline \multicolumn{2}{|c|}{ A-a } \\
\hline $\mathrm{a}$ & $\mathrm{A} 1$ & $\mathrm{a}$ \\
\hline $1-23$ & $24-49$ & $50-60$ \\
\hline $4+11+8$ & $4+17+5$ & $6+5$ \\
\hline
\end{tabular}

\section{Conclusions}

In the musical creation of the $20^{\text {th }}$ century, Shostakovich was always kept in the special position. As the representative of the Soviet music, his music gets close to the reality and it is filled with personal emotions. On the one hand, there is the special artistic charm in the works, thus he has had lots of fans and advocators. On the other hand, due to political causes, his works is often misunderstood. The explanation on his works tends to two extremes: loyal creation of the patriotic composer under the red political power or "private mark" sneer of different politicians under the totalitarian politics. The same composer has the completely opposite conclusion for the same works and this is not common in the entire music history.

\section{References}

[1] Written by Paul Robinson, translated by Zhou Binbin and checked by Yang Yandi, the Opera and Concept—from Mozart to Ster Lawes, East China Normal University Press, 2008.4

[2] Written by Joseph Kelman, translated by Zhu Dandan and Tang Yating, and checked by Tang Yating, Meditation on Music_Challenging Musicology, People’s Music Publishing House, 2008.4

[3] Yu Runyang, Sorrowful Chopin: Sorrowful Connotation Explanation in Chopin Music, Shanghai Conservatory of Music Press, 2008.6 